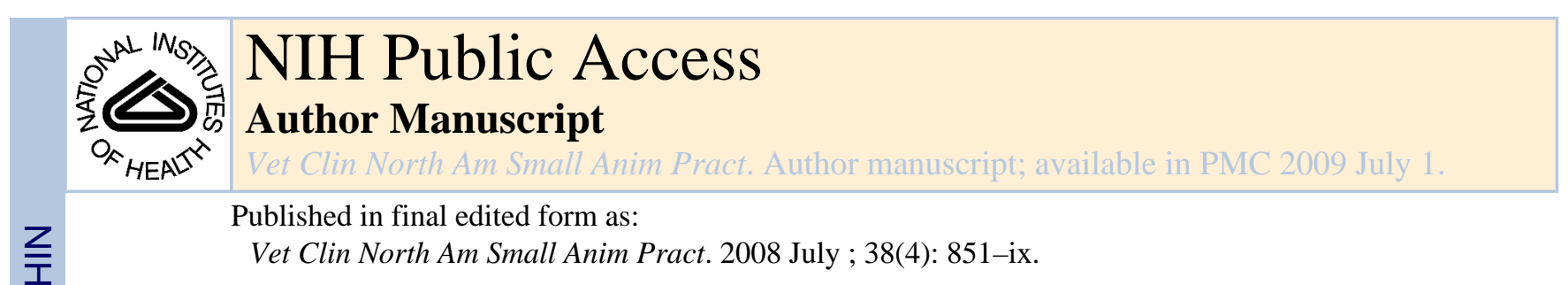

\title{
Rabies in small animals
}

\author{
Sarah N. Lackay, Yi Kuang, and Zhen F. Fu* \\ Department of Pathology, College of Veterinary Medicine, University of Georgia, Athens, GA 30602
}

\section{Introduction}

Rabies is an ancient disease and its history can be traced back more than 5000 years ago 24 . Despite significant scientific progress, rabies remains an important global disease. Annually, more than 55,000 human fatalities are reported, and millions of others require post-exposure treatment 38,39 . Most of the human cases occur in the developing nations of Asia and Africa, where dog rabies remains endemic or epizootic and thus is the main source for human exposure $^{24}$. In developed countries, human rabies has dramatically declined during the past 60 years as a direct consequence of routine vaccination of pet animals.

\section{Rabies in the United States}

In the United States, rabies was endemic in small animals, particularly in dogs, and thus was a major public health problem in the beginning of the last century. About 10,000 rabies cases were reported annually in dogs and cats ${ }^{43}$. Massive immunizations in domestic dogs and cats were initiated in the 1940s and 1950s. As a consequence, rabies in dogs and cats declined dramatically and now only a few hundred cases are reported each year ${ }^{43}$ (Fig 1). The rabies virus strains that used to be associated with dogs have disappeared during the last few years ${ }^{13}$. Viruses associated with small animals are derived from strains affecting wildlife animals.

Currently wildlife rabies is enzootic in the United States. Seven to eight thousand cases have been reported in wildlife annually during the past two decades 8,9 . Concurrently there are a few rabies enzootics occurring in the United States. The distribution of the terrestrial animal rabies epizootics is shown in Fig. $2^{45}$. Raccoon rabies has been spreading during the $1980 \mathrm{~s}$ and 1990s along the eastern seaboard ${ }^{17}$ and spreading westward in the new century 7 . Three different variants exist in striped skunks in longstanding reservoirs in California, the north central states, and the south central states ${ }^{16}$. Now skunks have been reported to be infected with raccoon and bat rabies variants in other states 26,33 . There are at least three fox rabies enzootics: arctic foxes in Alaska, along with red and gray foxes in the southeast ${ }^{5,12}$. Some of these terrestrial wildlife species may have acquired rabies virus from dogs a long time ago and have adapted to their own species and locations ${ }^{18}$. Others may have evolved from bat rabies variants ${ }^{33}$. Spillover from one species to another occurs from time to time 25,33 and may lead to spreading in the new species. The distribution of these terrestrial rabies epizootics are depicted in Fig. 2A and the phylogenetic relationship of these rabies variants in the United States is summarized in Fig. $2 \mathrm{~B}^{45}$. In addition to terrestrial animal rabies, bat rabies has been

\footnotetext{
*Corresponding author, zhenfu@uga.edu.
}

Publisher's Disclaimer: This is a PDF file of an unedited manuscript that has been accepted for publication. As a service to our customers we are providing this early version of the manuscript. The manuscript will undergo copyediting, typesetting, and review of the resulting proof before it is published in its final citable form. Please note that during the production process errors may be discovered which could affect the content, and all legal disclaimers that apply to the journal pertain. 
detected in all the 48 contiguous states and has been responsible for most of the human cases in the United States for the past 20 years 8 .

Wildlife rabies presents a health problem to domestic small animals, which in turn have a higher risk of transmission to humans due to their close contact with people. Rabies variants found in domestic animals include variants found in raccoons, north central skunks, south central skunks, Texas foxes, Texas dog-coyotes and California skunks 35 .

\section{Rabies in Dogs}

Dogs are the natural host for rabies. There are two forms of rabies-the excitatory or "furious" form, and the paralytic or "dumb" form 3,28 . There are several overlapping phases during the progression of the disease: the prodromal period, the furious period, and the paralytic period $^{3,28}$. However the clinical signs of rabies may vary among animals. The first stage lasts 2 to 3 days in dogs. During this phase, infected animals always show different behavior. The excitement phase may last up to a week, but sometimes animals progress directly from the prodromal phase to the paralytic stage. In the second period, animals suddenly become vicious and behave erratic. Within several days, the disease progresses to the paralytic period. In the last period, animals show paralysis first in the wound limb, and then in the neck and head. Disease in animals ends in respiratory failure and death ${ }^{3,28}$. The course of rabies typically lasts 3 to 8 days in dogs.

Recently a report described rabies symptoms in a 6 month old mixed breed female dog in Florida, which provides valuable insight into clinical presentation of rabies meningoencephalomyelitis. At presentation, the dog has a 3 day history of acute paraplegia, including areflexia, hyperesthesia, and non-painful swelling of the left second and third digits of the affected limb, eventually progressing to flaccid paralysis of the right pelvic limb. Analysis of lumbar CSF showed abnormally high protein, RBC, and WBC counts. Cytopathology revealed $78 \%$ lymphocytes, $21 \%$ mononuclear phagocytes, and $1 \%$ neutrophils. Serum testing for rabies neutralization antibodies using RFFIT assay was negative. EMG of left pelvic limb revealed moderate fibrillations and positive sharp waves suggestive of denervation/myopathy. No $\mathrm{M}$ wave could be generated for the left sciatic nerve, indicating a lack of axonal or neuromuscular transmission. F waves were also absent on the left sciatic, tibial and ulnar nerves. Results for the right limb, paravertebral muscles and thoracic limb muscles, and right sciatic, tibial and ulnar nerves were normal. Dementia, salivation and development of bilateral ventrolateral strabismus, focal and facial limb seizure and aggression occurred upon recovery from anesthesia. After euthanasia, the animal tested positive for raccoon rabies. Intracytoplasmic inclusion bodies could be seen in the brain stem and spinal cord. Degenerate and necrotic neurons were seen within thoracic and lumbar spinal cord 6 .

It is interesting to note that there have been cases of cerebral cysticercosis caused by the larval Taenia solium which mimics rabies virus infection in $\operatorname{logs}_{5} 51$. Additionally, there have been cases of cutaneous vasculitis associated with rabies vaccine administration in dogs, all with a similar inflammatory pattern of mononuclear cells (nonleukocytoclstic) $)^{40}$.

\section{Rabies in Cats}

Cats are the domestic animals most frequently reported rabid in the United States, and 200 to 300 cases are reported annually 31 . In one study in Pennsylvania, $44 \%$ of human post exposure prophylaxis (PEP) were due to exposure to a potentially rabid cat ${ }^{25}$. Factors influencing the increased incidence of rabies in cats include community tolerance of free ranging felines, as well as less frequent rabies vaccination due to more lenient state laws for cats as compared to dogs. Additionally, communities of feral cats exist, and people who care for these feral animals are at risk for coming into contact with rabies virus. Cats are predominantly affected by the 
variant of rabies virus endemic to the region in which they reside. For example, along the North American East coast, cats are commonly infected with raccoon rabies virus variant. However, cats can also contract bat rabies virus variants, as both cats and bats are nocturnal, and cats trap small animals such as bats ${ }^{27}$. Rabid cats display symptoms similar to those in dogs, but have a tendency to hide in secluded places and are often more vicious. Similar to recommendations for dogs, it is a common recommendation to confine and observe a cat involved in a human bite, in order to rule out rabies exposure 27,53 .

\section{Rabies in other small animals}

In addition to dogs and cats, rabies has been reported in other domestic small animals such as ferrets and rabbits. Two species of ferrets are common in the United States, the common ferret (Mustela putorius) and the black-footed ferret (Mustela nigripes). Ferrets have become popular companion animals in the United States. Ferrets were originally used to hunt small game and suckling animals, and may be attracted by the smell of milk ${ }^{49}$. Although rare, rabid pet ferrets have been reported in the United States ${ }^{13}$. Therefore, it has become increasingly important to be aware of clinical signs of rabies in domestic ferrets, to avoid potentially harmful interactions with their human owners. Clinical signs of paralytic rabies in ferrets included lethargy, ataxia, paresis, paraperesis, paralysis, bladder atony, constipation, hypothermia, inappetance and anorexia, abnormal or frequent vocalization, sneezing, parasthesia, and ptyalism (moist or matted fur around the mouth). Only about $10 \%$ of rabid ferrets in experimental infection showed aggressive behavior with rapid attack and destruction towards a paper applicator, most had no to mild interest in the applicator. It has been recommended to vaccinate all pet ferrets against rabies, and to consider rabies in the differential diagnosis of ferrets with acute personality change and/or paralysis 41,42 .

Rabies cases have also been reported in both rodents and lagomorphs, including a rabid pet guinea pig in 2003 which bit its owner in the clavicle. The guinea pig was later found to be infected with raccoon rabies virus. Between 1991 and 2001, the Wadsworth Center Rabies Lab received 7 lagomorphs, all pet domestics, 3 of which were exposed to a raccoon and 1 to a skunk. All 7 lagomorphs were infected with raccoon rabies virus ${ }^{23}$. However, rodents and lagomorphs should be considered "spillover" species, not reservoirs. Unfortunately often times no clinical signs are obvious in rabies-infected rodents. In 1972, a study on rabid squirrels showed that $1 / 2$ of infected animals that died of rabies showed no clinical signs 23,57 .

Two cases of rabies in domestic rabbits (Oryctolagus cuniculus) in Maryland in 1999 are worth note here. In both of these cases rabbits were sent home with owners after examination, and owners were instructed to hand or force feed rabbits which later died and were found to be rabid. Clinical signs of illness in these rabbits upon examination included weakness in forelimbs, palpable subcutaneous crepitus, slight intermittent head tremors, ear infection, nasal discharge, and anorexia. Upon readmission one rabbit exhibited heavy wheezing, inability to stand, head tilt, and bilateral conjunctivitis. The disease course culminated in a recumbent and non-responsive state. The case history of this rabbit included an attack by a raccoon in a rabies endemic area resulting in a wound to the ear and the rabbit being covered in saliva ${ }^{29}$. It is critical that rabies be considered in the differential diagnosis of any rabbit coming into contact with raccoons, especially those displaying neurological signs. Furthermore, discharging an animal that has been exposed to potentially rabid wildlife should be avoided, as should recommending owners to force feed these animals, bringing them in closer contact to a potentially rabid pet.

Despite natural infection of rabbits being rare, it is imperative to remember that rabbits are used for rabies diagnostic testing, and were used for creation of the fist rabies vaccine by Louis Pasteur in the 1880s. Rabbits are highly susceptible to rabies virus infection, have incubation 
periods between 2 and 3 weeks after intracerebral inoculation, and usually develop paralytic rabies. Experimentally infected rabbits display anorexia, fever, restlessness, weight loss, and neurological signs such as teeth grinding, head tremors, poor coordination of the hind limbs, and ascending paralysis. The affected rabbit usually dies within 3-4 days ${ }^{29}$. Veterinarians should advise patients that no rabies vaccine is available for rabbits, so prevention is essential. Rabbits should be kept indoors or kept in elevated hutches without exposed wire mesh floors, and rabbits should be supervised at all times when exercising outdoors 29 .

\section{Laboratory diagnosis for animal rabies}

Clinical signs are good indication for rabies in small animals. However rapid and accurate laboratory diagnosis for animal rabies is important for confirmation. In addition, many animals may not show typical signs of rabies. Usually rabid or suspected rabid wild animals are road kill or otherwise deceased when brought into diagnostic laboratories. Laboratory diagnosis is very important because it provides not only data for epidemiological investigation of animal rabies, but also guidance for initiation of PEP in affected people ${ }^{14}$.

\section{Direct florescent antibody assay (dFA)}

The most frequently used method for rabies diagnosis in the laboratory is $\mathrm{dFA}^{420,21}$. Usually, brain smears or brain imprints from rabid or suspected rabid animals are reacted with fluorescein isothiocyanate (FITC)-conjugated-anti-rabies N antibodies ${ }^{4,55}$. When observed under a fluorescent microscope, the green-fluorescent foci will show the rabies virus antigen (Fig. 3A). dFA is rapid, economical, and sensitive for laboratory diagnosis of animal rabies. Rabies antigens can be detected by the specific antibody; however, they should be differentiated from the non-specific background.

\section{Direct rapid immunohistochemistry test (dRIT)}

Recently, the CDC developed the $\mathrm{dRIT}^{32}$, which is similar to dFA. Brain smears or imprints on glass slides are fixed with $10 \%$ buffered formalin ${ }^{32}$. According to standard immunohistochemical staining, the virus antigen can be detected by anti-rabies $\mathrm{N}$ monoclonal antibody and examined under a light microscope. The sensitivity and specificity of dRIT is equivalent to that of the $\mathrm{dFA}^{32}$.

\section{Virus Isolation}

Mouse inoculation is a world health organization (WHO) recommended method to confirm dFA when the result is negative ${ }^{3056}$. Usually, brain suspension or spinal fluid from rabid or suspected rabid animals is intracerebrally inoculated into mouse brain. Two mice are killed every 2 days post infection until day 20 and brain smears are subjected to dFA. The $50 \%$ mouse intracerebral lethal dose $\left(\right.$ MICLD $\left._{50}\right)$ can be calculated ${ }^{46}$. Virus isolation can also be performed in cell culture, usually on neuroblastoma cells 59 . The $50 \%$ tissue culture infective dose $\left(\right.$ TCID $_{50}$ ) can be calculated ${ }^{46}$. Cell culture inoculation is as sensitive as the mouse inoculation test ${ }^{47}$ and it requires less time to obtain results.

\section{Reverse transcriptase Polymerase chain reaction (RT-PCR)}

RT-PCR is a newly developed method for rabies diagnosis ${ }^{4,50}$. RT-PCR is very useful when sample size is small such as saliva and spinal fluid. Viral RNA is amplified by RT-PCR with primers usually designed from the $\mathrm{N}$ gene, the most conserved gene in rabies virus. RT-PCR for rabies diagnosis is as rapid as dFA and is as sensitive as mouse inoculation test ${ }^{34}$. RT-PCR is also widely used in epidemiological investigation and outbreak studies. When combined with sequencing, this method can also be used to differentiate rabies virus variants from 
multiple species of animals $19,35,50,54$. Viral variants can also be differentiated with different monoclonal antibodies in an indirect fluorescent antibody assay 22,35 .

\section{Histopathology and Immunohistochemistry}

Rabies diagnosis in small animals can also be performed on brain tissues by histopathology and immunohistochemistry ${ }^{44}$. Histopathology may show lymphocytic inflammation, perivascular cuffing, gliosis, and neurodegeneration ${ }^{52}$. Inflammation is diffuse in neuraxis. The parenchymal glial response is at first microglial but later mixed with astrocytes. Neurondegeneration is often not severe ${ }^{48}$. The severity of inflammation may vary between animal species. Sometimes, a spongiform encephalopathy with vacuolation in the gray matter can be observed 15 . Negri bodies which are ovoid eosinophilic intracytoplasmic inclusions 11,58 are a hallmark for rabies diagnosis. Yet Negri bodies are not found in all rabies cases $^{52}$.

In fixed brain tissue, immunohistochemistry can be used to confirm diagnosis (Fig. 3B). By using the rabies specific antibody and avidin-biotin colorimetric detection system, the virus can be detected. Antigen-positive neurons can be found in the brain and spinal cord.

\section{Detection of rabies virus-specific antibodies}

Detection of specific antibodies can be used as diagnostic tools for rabies. There are many methods that have been developed to detect rabies-specific antibodies. Rapid fluorescent focus inhibition test (RFFIT) is the method used most often to detect virus neutralizing antibodies 4,10 . ELISA has also been used to detect virus-specific antibodies when the ELISA plate is coated with rabies virus antigens ${ }^{36,37}$. Since antibodies take several days to develop, this method is rarely used in diagnosis of animal rabies. Rather detection of virus-specific antibodies is often used in vaccination studies.

\section{Rabies control in domestic small animals}

Rabies control in small animals is by routine immunization with inactivated rabies virus vaccines, which have been approved for dogs, cats, and ferrets. First vaccination is carried out at three months of age and followed by a booster one year later. Subsequent immunization is carried out annually or triennially depending on the type of vaccines used ${ }^{1}$. Recently a recombinant canarypox vaccine is licensed for cats with a similar immunization schedule ${ }^{2}$. Currently, it is required by law that dogs and cats be vaccinated against rabies.

\section{Conclusion}

Rabies in small animals has been dramatically reduced in the United States since the introduction of rabies vaccination of domestic animals in the 1940s. As a consequence, the number of human rabies cases has declined to only a couple per year. During the last several years, dog rabies variant has almost disappeared completely. However, rabies in wildlife has skyrocketed. At the present, there are many concurrent rabies epizootics in wildlife in the US: raccoon rabies along the eastern seaboard, skunk rabies in the central states and California, artic fox rabies in Alaska, and red and gray fox rabies in the southwestern states. In addition, bat rabies is endemic in the 48 contiguous states. Each wildlife species carries its own rabies variant(s). These wildlife epizootics present a constant public health threat as well as the danger of reintroducing rabies to domestic animals. Vaccination is the key to prevent both rabies in small animals and rabies transmission to humans. 


\section{Reference}

1. The National Association of State Public Health Veterinarians. Compendium of animal rabies prevention and control, 2000. J Am Vet Med Assoc 2000;216:338. [PubMed: 10668529]

2. Compendium of animal rabies prevention and control, 2006. J Am Vet Med Assoc 2006;228:858. [PubMed: 16536693]

3. Rabies, in What every dog owner should know about rabies. http://www.canismajor.com/dog/rabies.html

4. Rabies - Bulletin - Europe, in Rabies Information System of the WHO Collaboration Centre for Rabies Surveillance and Research. 2007.

5. Ballard WB, Follmann EH, Ritter DG, et al. Rabies and canine distemper in an arctic fox population in Alaska. J Wildl Dis 2001;37:133. [PubMed: 11272487]

6. Barnes HL, Chrisman CL, Farina L, et al. Clinical evaluation of rabies virus meningoencephalomyelitis in a dog. J Am Anim Hosp Assoc 2003;39:547. [PubMed: 14736720]

7. Biek R, Henderson JC, Waller LA, et al. A high-resolution genetic signature of demographic and spatial expansion in epizootic rabies virus. Proc Natl Acad Sci U S A 2007;104:7993. [PubMed: 17470818]

8. Blanton JD, Hanlon CA, Rupprecht CE. Rabies surveillance in the United States during 2006. J Am Vet Med Assoc 2007;231:540. [PubMed: 17696853]

9. Blanton JD, Krebs JW, Hanlon CA, et al. Rabies surveillance in the United States during 2005. J Am Vet Med Assoc 2006;229:1897. [PubMed: 17173527]

10. Budzko DB, Charamella LJ, Jelinek D, et al. Rapid test for detection of rabies antibodies in human serum. J Clin Microbiol 1983;17:481. [PubMed: 6841582]

11. Butts JD, Bouldin TW, Walker DH. Morphological characteristics of a unique intracytoplasmic neuronal inclusion body. Acta Neuropathol (Berl) 1984;62:345. [PubMed: 6328831]

12. Carey AB. The Ecology of Red Foxes, Gray Foxes, and Rabies in the Eastern United States. Wildlife Society Bulletin 1982;10:18.

13. CDC. Epidemiology: United States Rabies Surveillance Data, 2006. 2007.

14. CDC. First human death associated with raccoon rabies--Virginia, 2003. MMWR Morb Mortal Wkly Rep 2003;52:1102. [PubMed: 14614408]

15. Charlton KM, Casey GA, Webster WA, et al. Experimental rabies in skunks and foxes. Pathogenesis of the spongiform lesions. Lab Invest 1987;57:634. [PubMed: 3695410]

16. Charlton KM, Webster WA, Casey GA, et al. Skunk rabies. Rev Infect Dis 1988;10:S626. [PubMed: 3206070]

17. Childs JE, Curns AT, Dey ME, et al. Predicting the local dynamics of epizootic rabies among raccoons in the United States. Proc Natl Acad Sci U S A 2000;97:13666. [PubMed: 11069300]

18. Clark KA, Neill SU, Smith JS, et al. Epizootic canine rabies transmitted by coyotes in south Texas. J Am Vet Med Assoc 1994;204:536. [PubMed: 8163414]

19. Crepin P, Audry L, Rotivel Y, et al. Intravitam diagnosis of human rabies by PCR using saliva and cerebrospinal fluid. J Clin Microbiol 1998;36:1117. [PubMed: 9542950]

20. Dean, DJ.; Ableseth, MK. Laboratory techniques in rabies. World Health Organization, Monogr Ser; 1973.

21. Dean, DJ.; Ableseth, MK.; Atanasiu, P. Laboratory techniques in rabies. ed 4thGeneva: World Health Organization; 1966.

22. Dean, DJ.; Ableseth, MK.; Atanasiu, P. Laboratory techniques in rabies. ed 4thGeneva: World Health Organization; 1996.

23. Eidson M, Matthews SD, Willsey AL, et al. Rabies virus infection in a pet guinea pig and seven pet rabbits. J Am Vet Med Assoc 2005;227:932. [PubMed: 16190592]

24. Fu ZF. Rabies and rabies research: past, present and future. Vaccine 1997;15:S20. [PubMed: 9218287]

25. Gordon ER, Curns AT, Krebs JW, et al. Temporal dynamics of rabies in a wildlife host and the risk of cross- species transmission. Epidemiol Infect 2004;132:515. [PubMed: 15188720]

26. Guerra MA, Curns AT, Rupprecht CE, et al. Skunk and raccoon rabies in the eastern United States: temporal and spatial analysis. Emerg Infect Dis 2003;9:1143. [PubMed: 14519253]

27. Jackson, AC.; Wunner, WH., editors. Rabies. ed 2. Academic Press; 2007. 
28. Jeffrey, E.; Barlough, FWS.; Richards, James R. Max's house rabies. in: http://maxshouse.com/rabies.htm

29. Karp BE, Ball NE, Scott CR, et al. Rabies in two privately owned domestic rabbits. J Am Vet Med Assoc 1999;215:1824. [PubMed: 10613216]

30. Koprowski, H. Laboratory techniques in rabies: the mouse inoculation test. Monogr Ser World Health Organ; 1973.

31. Krebs JW, Rupprecht CE, Childs JE. Rabies surveillance in the United States during 1999. J Am Vet Med Assoc 2000;217:1799. [PubMed: 11132881]

32. Lembo T, Niezgoda M, Velasco-Villa A, et al. Evaluation of a direct, rapid immunohistochemical test for rabies diagnosis. Emerg Infect Dis 2006;12:310. [PubMed: 16494761]

33. Leslie MJ, Messenger S, Rohde RE, et al. Bat-associated rabies virus in skunks. Emerg Infect Dis 2006;12:1274. [PubMed: 16965714]

34. Macedo CI, Carnieli P Jr, Brandao PE, et al. Diagnosis of human rabies cases by polymerase chain reaction of neck-skin samples. Braz J Infect Dis 2006;10:341. [PubMed: 17293923]

35. McQuiston JH, Yager PA, Smith JS, et al. Epidemiologic characteristics of rabies virus variants in dogs and cats in the United States, 1999. J Am Vet Med Assoc 2001;218:1939. [PubMed: 11417737]

36. Mebatsion T, Frost JW, Krauss H. Enzyme-linked immunosorbent assay (ELISA) using staphylococcal protein A for the measurement of rabies antibody in various species. Zentralbl Veterinarmed B 1989;36:532. [PubMed: 2816177]

37. Mebatsion T, Sillero-Zubiri C, Gottelli D, et al. Detection of rabies antibody by ELISA and RFFIT in unvaccinated dogs and in the endangered Simien jackal (Canis simensis) of Ethiopia. Zentralbl Veterinarmed B 1992;39:233. [PubMed: 1642078]

38. Meslin FX. Current situation on human rabies control and anti-rabies vaccination. Sante 1994;4:203. [PubMed: 7921688]

39. Meslin FX, Fishbein DB, Matter HC. Rationale and prospects for rabies elimination in developing countries. Curr Top Microbiol Immunol 1994;187:1. [PubMed: 7859487]

40. Nichols PR, Morris DO, Beale KM. A retrospective study of canine and feline cutaneous vasculitis. Vet Dermatol 2001;12:255. [PubMed: 11906650]

41. Niezgoda M, Briggs DJ, Shaddock J, et al. Pathogenesis of experimentally induced rabies in domestic ferrets. Am J Vet Res 1997;58:1327. [PubMed: 9361901]

42. Niezgoda M, Briggs DJ, Shaddock J, et al. Viral excretion in domestic ferrets (Mustela putorius furo) inoculated with a raccoon rabies isolate. Am J Vet Res 1998;59:1629. [PubMed: 9858418]

43. Noah DL, Drenzek CL, Smith JS, et al. Epidemiology of human rabies in the United States, 1980 to 1996. Ann Intern Med 1998;128:922. [PubMed: 9634432]

44. Palmer DG, Ossent P, Suter MM, et al. Demonstration of rabies viral antigen in paraffin tissue sections: comparison of the immunofluorescence technique with the unlabeled antibody enzyme method. Am J Vet Res 1985;46:283. [PubMed: 3882030]

45. Real LA, Russell C, Waller L, et al. Spatial dynamics and molecular ecology of North American rabies. J Hered 2005;96:253. [PubMed: 15677743]

46. Reed L, Muench H. A simple method of estimating fifty percent endpoints. Am J Hyg 1938;27:493.

47. Rudd RJ, Trimarchi CV. Development and evaluation of an in vitro virus isolation procedure as a replacement for the mouse inoculation test in rabies diagnosis. J Clin Microbiol 1989;27:2522. [PubMed: 2681254]

48. Rupprecht CE, Dietzschold B. Perspectives on rabies virus pathogenesis. Lab Invest 1987;57:603. [PubMed: 3320516]

49. Ryland, LM.; Bernard, SL.; Gorham, JR. A clinical guide to the pet ferret. In: Trenton, NJ., editor. Veterinary Learning Systems, c1997. 1997. p. 122

50. Sacramento D, Bourhy H, Tordo N. PCR technique as an alternative method for diagnosis and molecular epidemiology of rabies virus. Mol Cell Probes 1991;5:229. [PubMed: 1714538]

51. Suja MS, Mahadevan A, Madhusudana SN, et al. Cerebral cysticercosis mimicking rabies in a dog. Vet Rec 2003;153:304. [PubMed: 14509578]

52. Summers, BA.; F.Cummings, J.; deLahunta, A. Veterinary Neuropathology. Mosby; 1994. 
53. Tepsumethanon V, Lumlertdacha B, Mitmoonpitak C, et al. Survival of naturally infected rabid dogs and cats. Clin Infect Dis 2004;39:278. [PubMed: 15307040]

54. Tordo, N.; Sacramento, D.; HB. Laboratory techniques in rabies. ed fourthGeneva: World Health Organization; 1996.

55. Trimarchi CV, Debbie JG. Standardization and quantitation of immunofluorescence in the rabies fluorescent-antibody test. Appl Microbiol 1972;24:609. [PubMed: 4564045]

56. Webster WA, Casey GA, Charlton KM. The mouse inoculation test in rabies diagnosis: early diagnosis in mice during the incubation period. Can J Comp Med 1976;40:322. [PubMed: 793696]

57. Winkler, WG. Rodent Rabies. In: Baer, GM., editor. The natural history of rabies. 2nd ed.. Boca Raton, FL: CRC Press, INC; 1991. p. 405

58. Yang LM, Zhao LZ, Hu RL, et al. A novel double-antigen sandwich enzyme-linked immunosorbent assay for Measurement of Antibodies against rabies virus. Clin Vaccine Immunol 2006;13:966. [PubMed: 16893999]

59. Zanoni R, Hornlimann B, Wandeler AI, et al. Rabies Tissue Culture Infection Test as an Alternative for the Mouse Inoculation Test. ALTEX 1990;7:15. [PubMed: 11182897] 


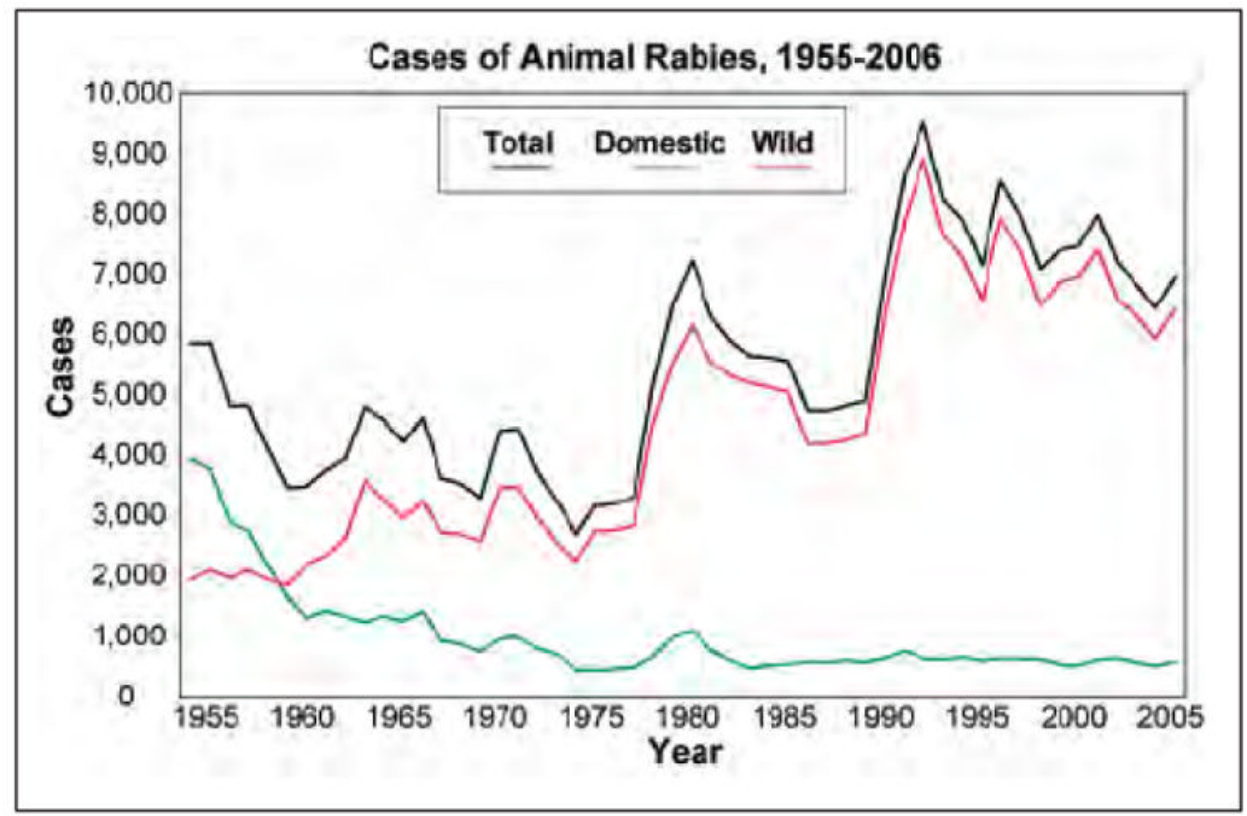

Fig. 1.

Cases of animal rabies in the United States, by year, $1955-2006 .{ }^{8}$ Courtesy of http://www.cdc.gov/rabies/docs/rabies_surveillance_us_2006.pdf 
A

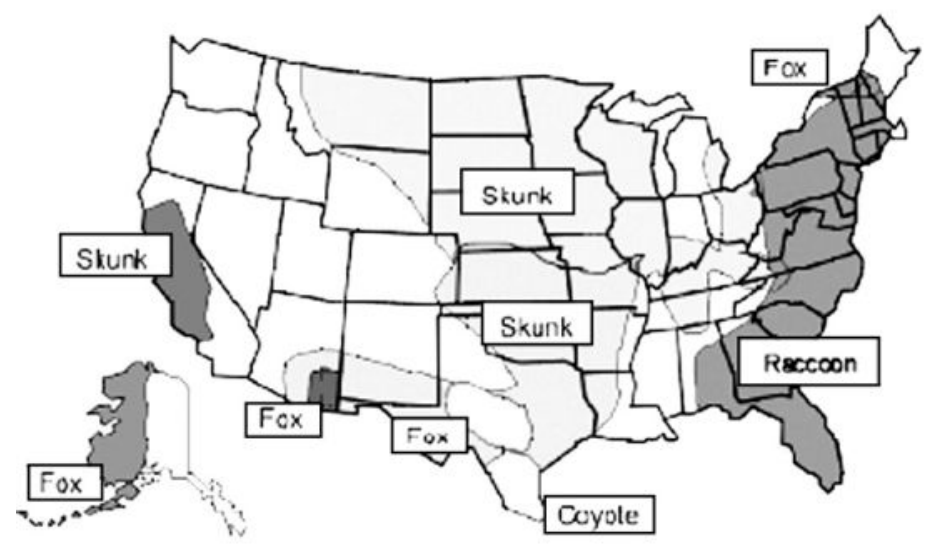

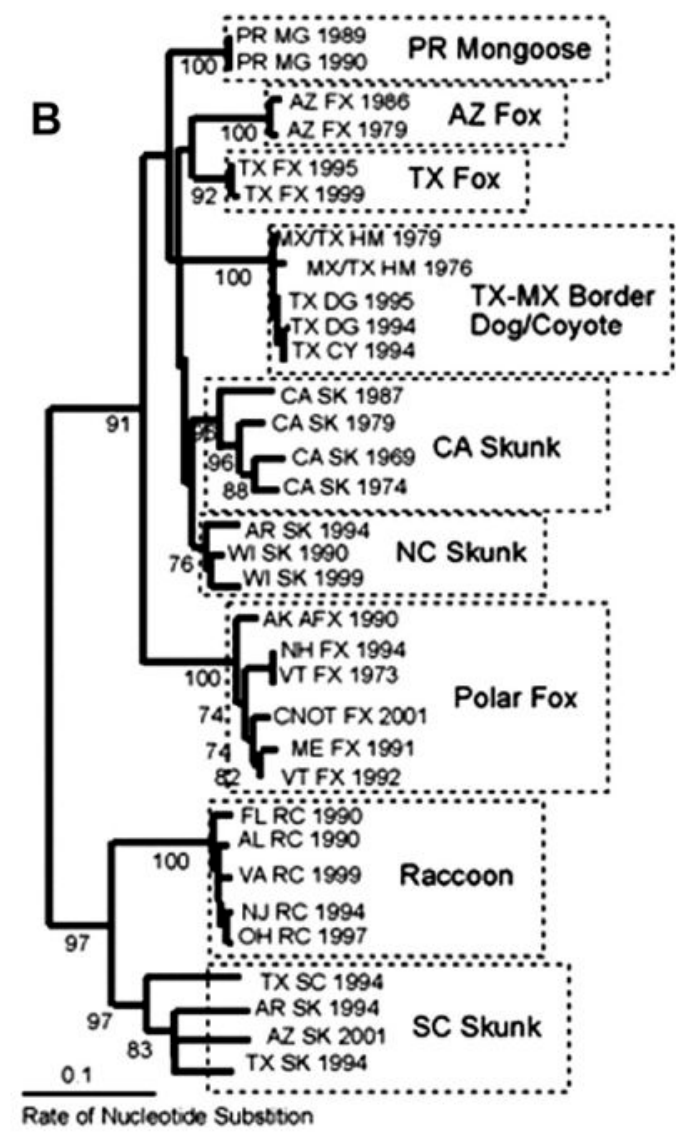

Fig. 2.

(A) Geographic distribution of the major terrestrial carnivore hosts of rabies virus variants. Each region is largely characterized by a unique rabies variant specific to a single carnivore host. (B) Neighbor-joining tree for nucleotide sequence of a 320-bp region of the nucleoprotein gene of selected RABV isolates from the United States, Mexico, and Canada. Each group of virus isolates that was sequenced to illustrate the unique RABV variants associated with terrestrial carnivores is boxed. The Polar Fox variant (Artic and red fox) is no longer considered enzootic in the United States. Bootstrap values are shown at the branching point for clades recovered in .700/1000 iterations of the data. ABLV was used as the outgroup and to root the tree. Samples from a rabid fox in Ontario, Canada (CN OT FX 2/4), and from two human rabies cases with exposures to rabid dogs in Mexico (MX/TX HM 1976 and 1979) are included to show variants of RABV shared across international boundaries. U.S. samples are identified by a two-letter abbreviation for the state and animal from which the sample originated, followed by the year the case occurred. With the exception of the Canadian sample (GenBank accession U11735), all RABV sequences were derived from samples in a virus repository at CDC. (Taken from Real et $\mathrm{al}^{45}$ ) 

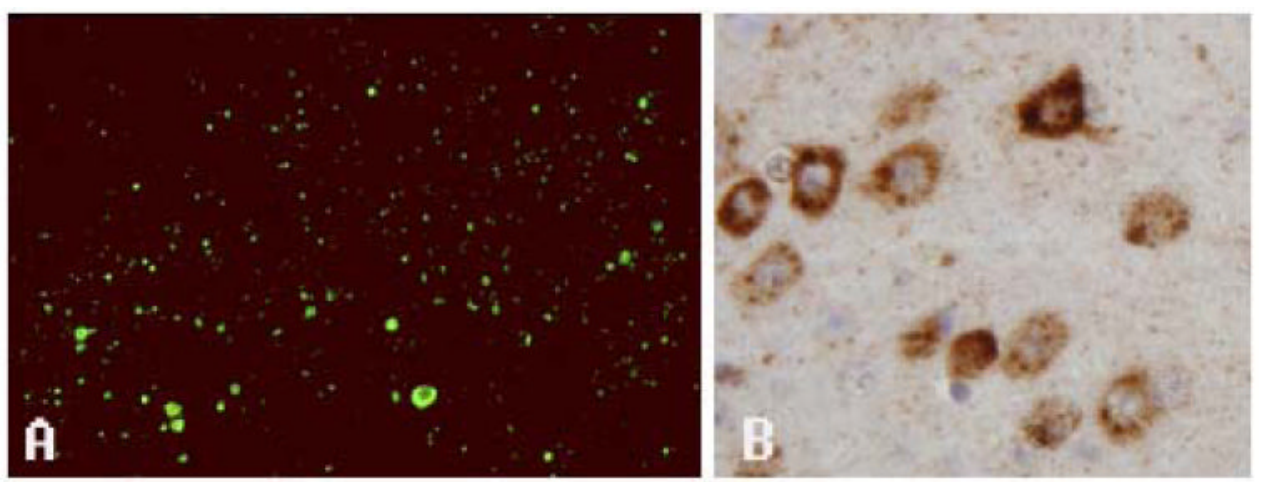

Fig. 3.

Detection of rabies virus antigens by dFA (A) and immunohistochemistry (B). The virus foci show positive stains with green-fluorescent color (A). Courtesy of

http://www.cdc.gov/rabies/diagnosis.html. The paraffin embedded slide was stained by antiRV nucleoprotein monoclonal antibody 802-2. Rabies antigens in the cytoplasm and inclusions are shown in brown (using diaminobenzidine as the substance) and the cell nuclei are shown in blue (B). 